\title{
نسبة مساهمة بعض العوامل المؤثرة في تنفيذ درس التربية الرياضية للمدارس المتوسطة في محافظة أربيل
}

\author{
إبراهيم محمد مصطفى ' \\ ' ل مكول التربية الرياضية، جامعة كويه، إقليم وكردستان، العراق
}

لإنَّ عملية التدريس هي عبارة عن سلسلة من العلاقات المستمرة تنشأ بين المعلم والطالب والمنهج ، وإنَّ هذه العلاقات تساعد الطالب على النطور بوصفه فردا أو مشاركا في

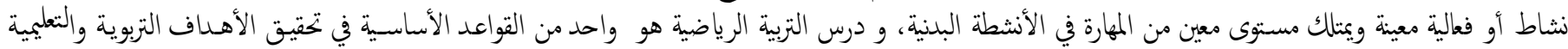

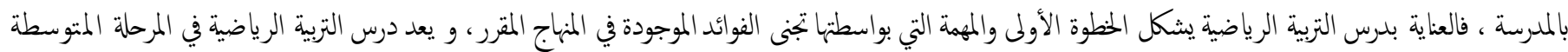

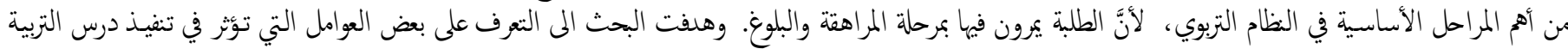

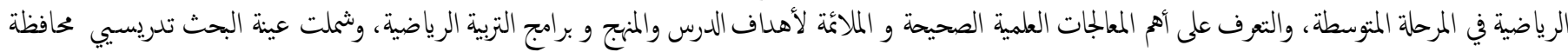

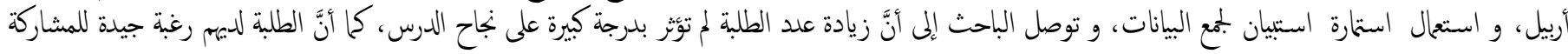

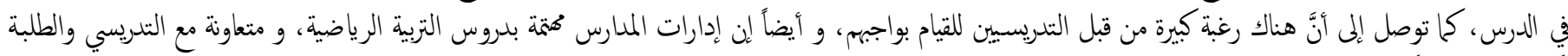

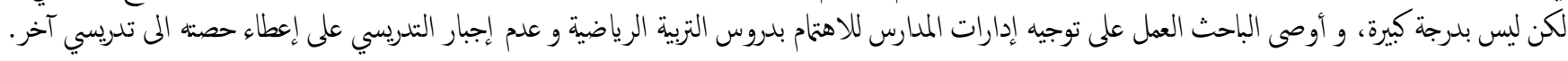
الكلمات الدالة: الأنشطة البدنية، درس التربية الرياضية، محافظة أربيل، الملارس المتوسطة، نسبة المساهة

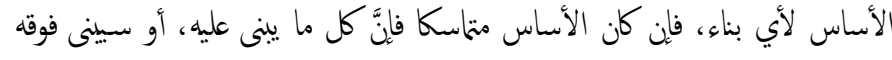

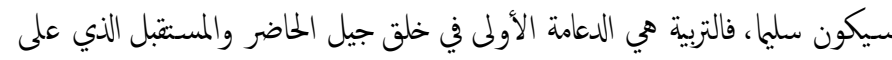

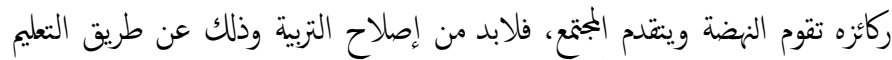

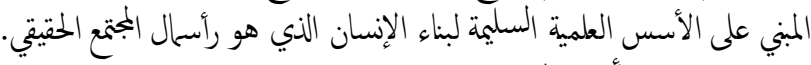

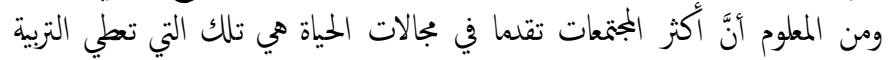

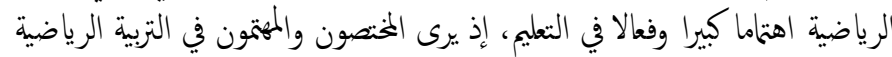

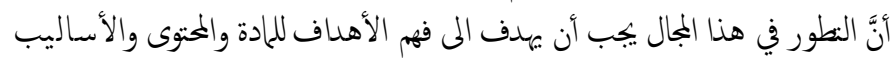

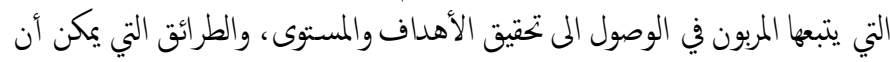

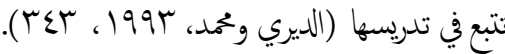

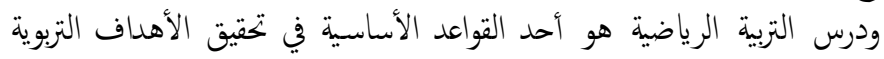

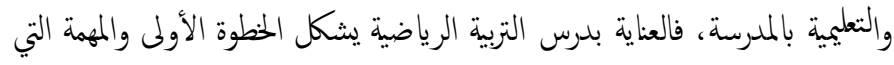

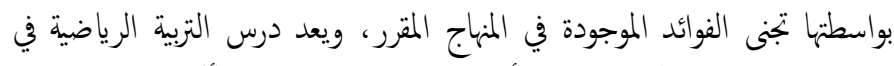

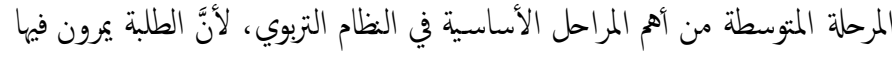

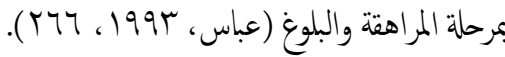

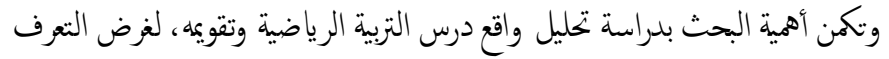

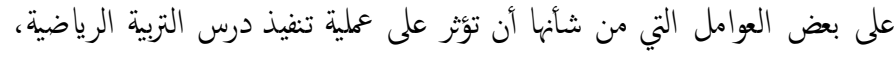

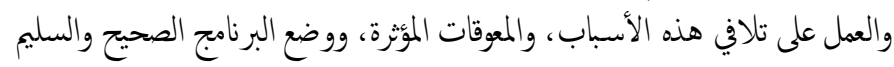

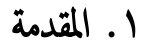

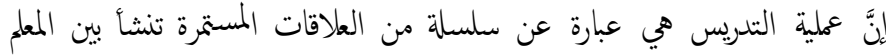

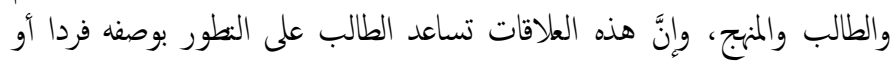
مشاركا في نشاط أو فعلية معينة ويمتلك مستوى معين من المهات المهارة في الأنشطة البندية.

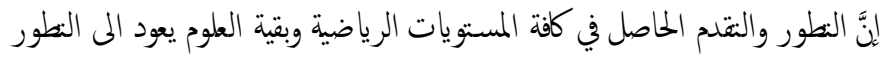

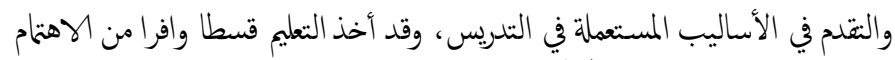

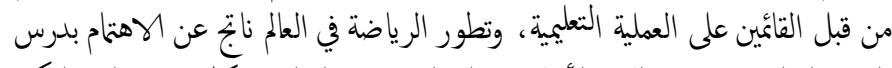

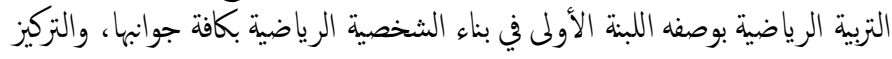

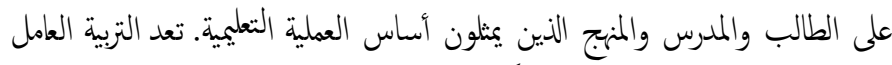

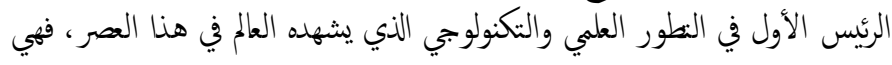

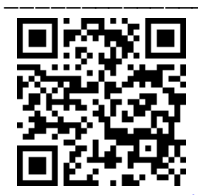

مجلة جامعة كيه للعلوم الإنسانية والاجتماعية

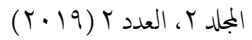

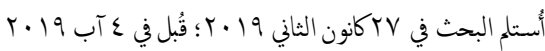

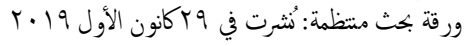

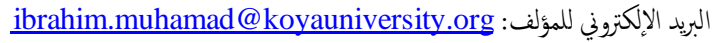

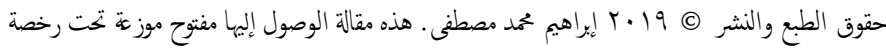

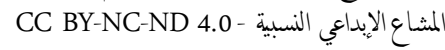


ونتأجكهم دقيقة وحقيقية

البات

تعد الأداة ثابتة إذا أعطت النتائُ نفسا في قياسها للظاهرة مرات متنظالية (العجيلي

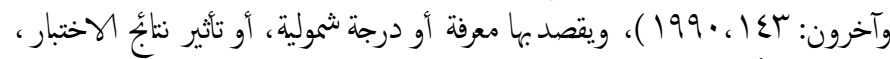

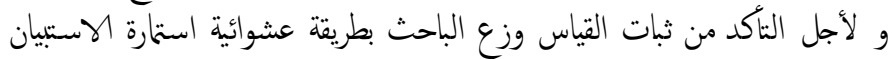

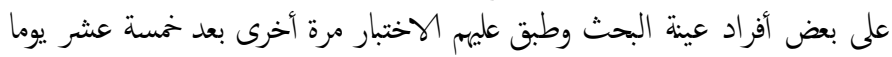

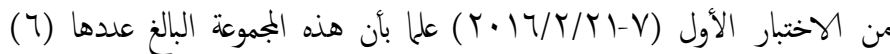

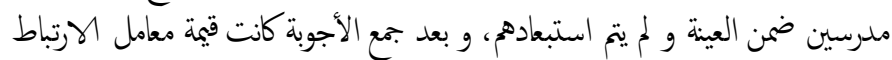

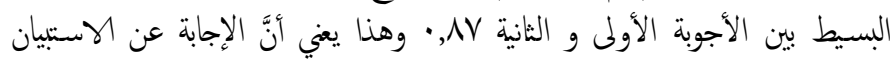

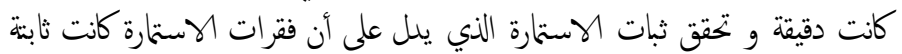

$$
\text { وتقيس الهدف الموضوع من أجلها. }
$$

ا ـع الوسائل الإحصائية

لقد استعمل الباحث:

- معامل الارتباط البسيط لبيان ثبات الهستبيان. - النسبة المؤية كوسيلة إحصائية لاستخراج النسبة المبيطية الحتيقية التي تيبن فاعلية العبارات لموبحة لعينة البحث.

\section{r r عرض النتاجُ وتحليلها ومناقثتها}

r. أعرض ومناقثة تناجُ المحور الأول الخاصة بالطلبة

\begin{tabular}{|c|c|c|c|c|c|}
\hline \multicolumn{6}{|c|}{ 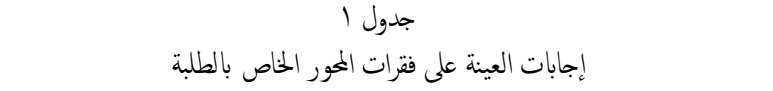 } \\
\hline جداًّة & قليل \% & متو سط & كثير\% & المحور الأول: الطلبة & \\
\hline صفر & 1..19 & $\overline{V 1.9 Y}$ & 19.19 & زليى نجاح عدد الطرسة تؤثر سلبًا & 1 \\
\hline$r, 0$. & IY.r. & $V . .1 V$ & $1 \varepsilon . \cdot r$ & الطلبة لمشَّاركة فعالياليات من قبل & $r$ \\
\hline$r, 0$. & $1 \varepsilon .+r$ & $71 . \leqslant \varepsilon$ & $1 \varepsilon . \cdot r$ & 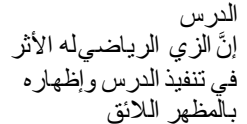 & $r$ \\
\hline
\end{tabular}

يتيبين من الجدول (1) بأنَّ الإجابة على الفقرة الأولى من محور الطلبة نسبة تأثيرها

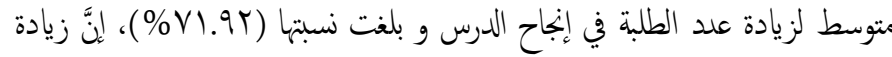

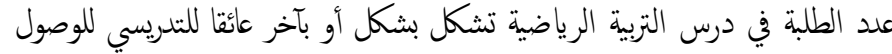

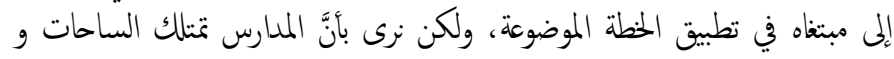

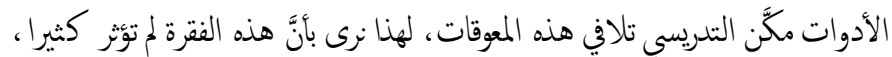

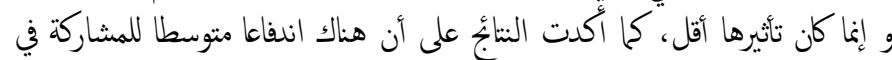

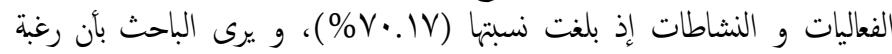

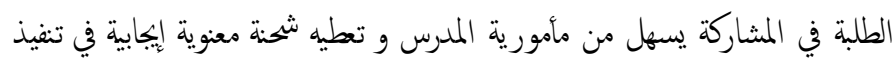

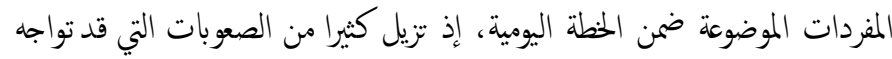

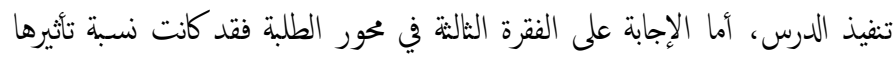

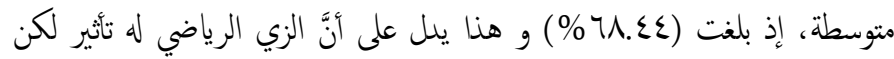

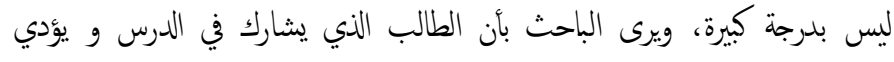

لتحقيق أهداف الدروس التعليمية والتربوية

(1. ا مشكلة البحث

أصبحت الحاجة المى الارتقاء بمستوى تدريس مادة التربية الرياضية في ملارسنا عوما

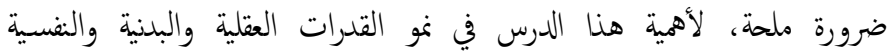

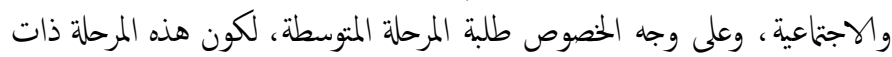

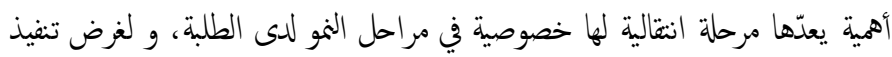

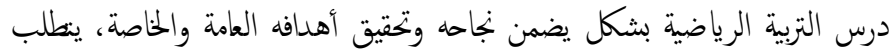

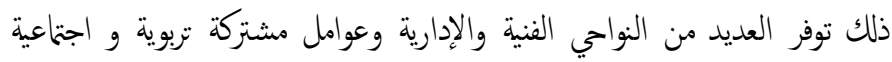

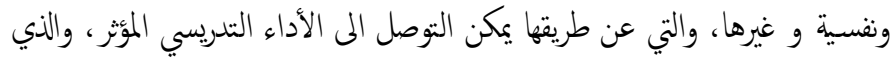

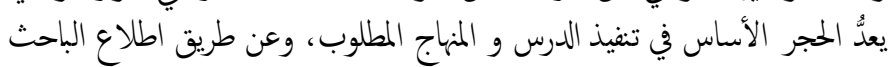

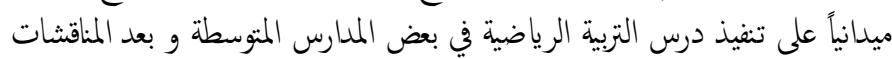

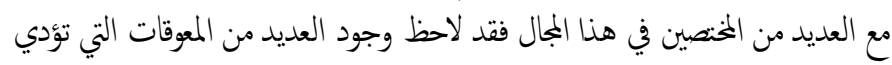

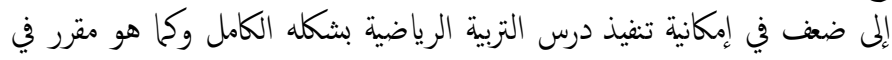

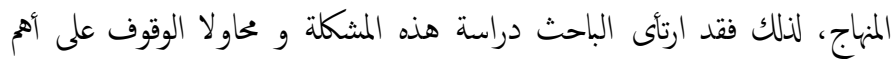

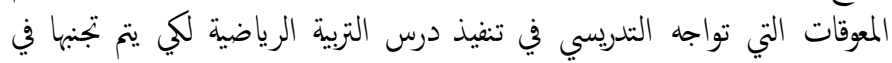
المستقبل، للخروج بدرس التربية الرياضية على شكله الصحيح و المؤزر.

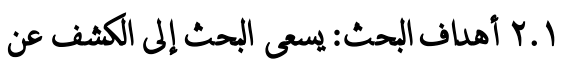

1. العوامل المؤثرة في تنفيذ درس التربية الرياضية لمرحلة المتوسطة.

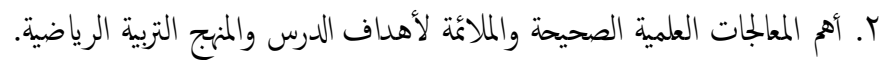

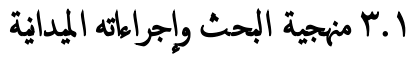

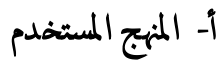

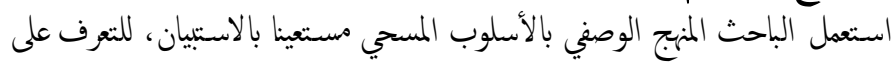

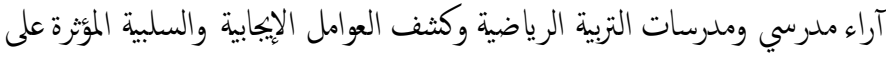
تهناج التبية الرياضية. ب- مجتمع البحث وينته

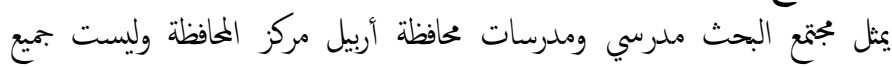

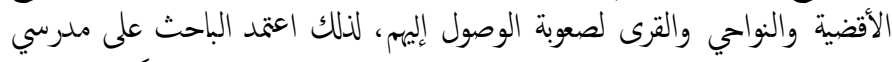

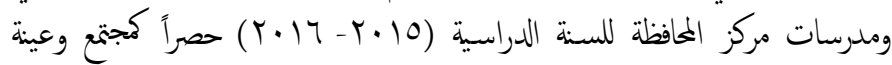

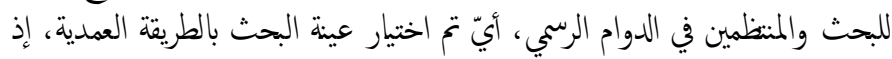

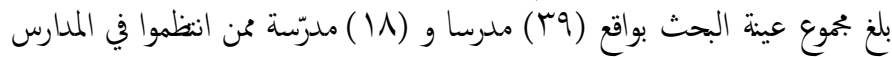
المتوسطة في مليرية النشاط الرياضي والكشفي. ج- جأداة البحث

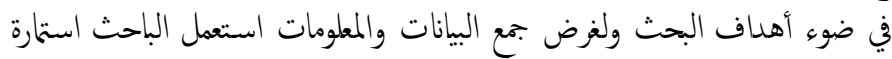

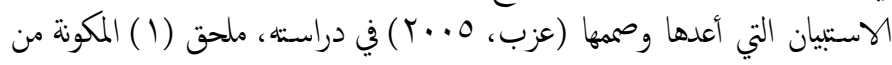

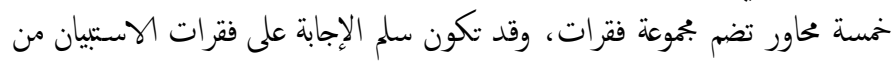

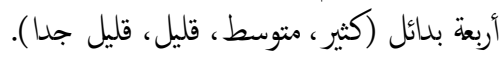

الصدق

تعد الأداة صادقة فيا وضعت لقياسه، وللتاكد من صدقها في الدراسة الحالية تم عرضها

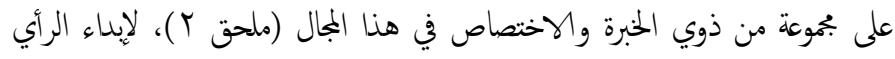

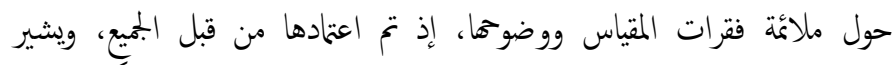

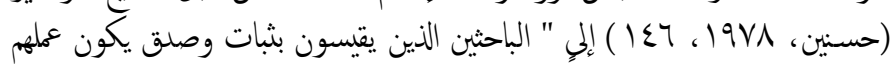


يتبين من الجدول (ب) بأن الإجابة على الفقرة الأولى من المحور الخاص بمدرس التزبية

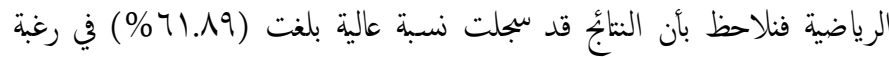
المدرس للقيام بواجبه في تنفيذ درس التببة الرياضية، و هي ناحية إيمابية جلا، الريا،

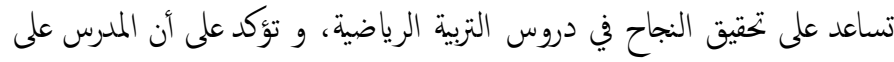

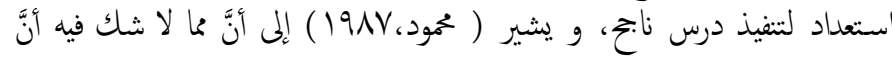

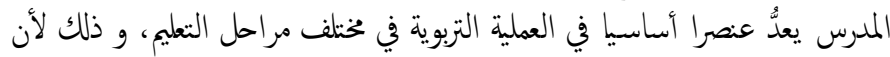

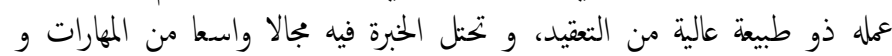

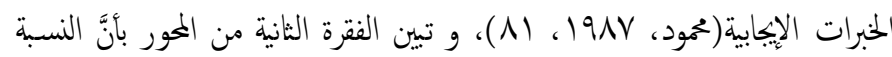

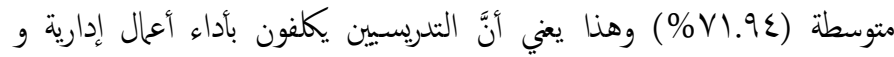

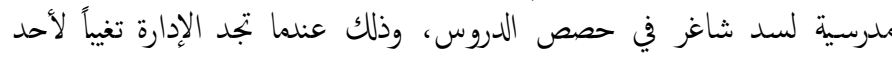

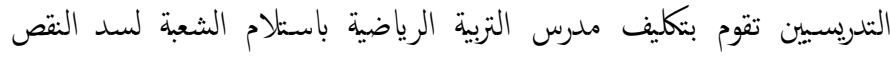

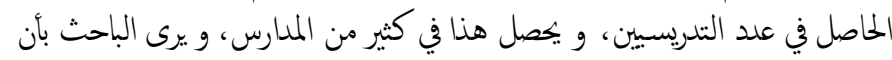

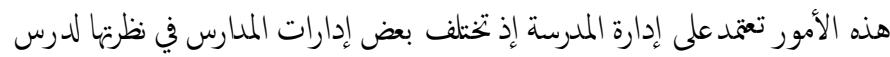

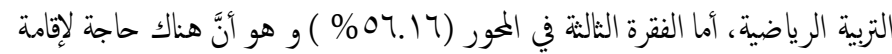

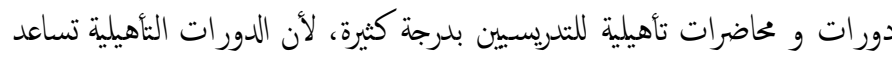

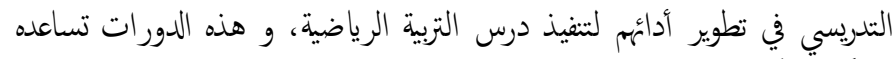

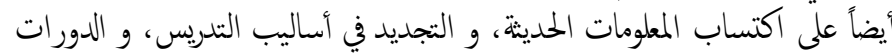

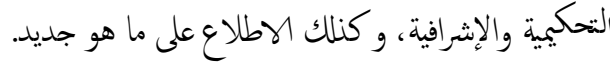

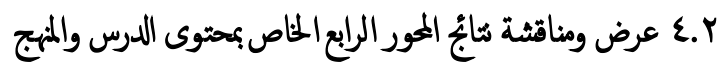
جدول ع

إجابات العينة على فقرات محور محتوى الدرس والمنهج

\begin{tabular}{|c|c|c|c|c|}
\hline قليل جدأ \% & قليل \% & متوسط \% & كثير \% & محتوى الدرس والمنهج \\
\hline 1.10 & $\overline{~ Y r . \wedge . ~}$ & $71 . \leqslant \leqslant$ & $v^{\prime} .1$ & 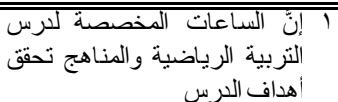 \\
\hline $0 . r V$ & $r \Lambda . \cdot v$ & $\leqslant 9.14$ & $1 V .0 \leqslant$ & 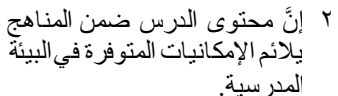 \\
\hline صفر & Ir.rk & ד. דז & Tr..T & r ب يجد المدرس معوقات في الالتزام \\
\hline$v_{.} \cdot 1$ & $r^{1} . \cdot T$ & $\leq 0 . T Y$ & r.T. & 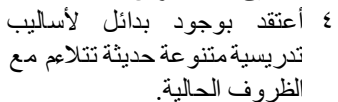 \\
\hline
\end{tabular}

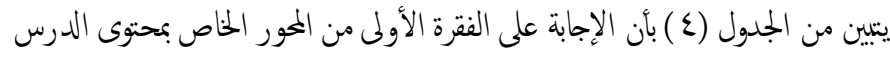

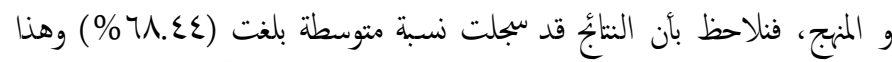
يدل بأن الساعات المخصصة لدرس التربية الرياضية مقبولة نسبياً في تحقيق الأهداف ألماف

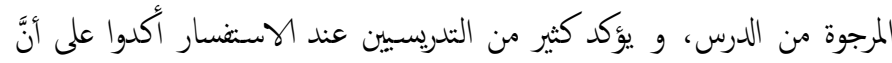

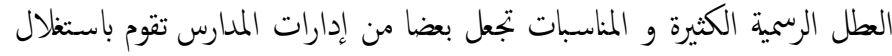

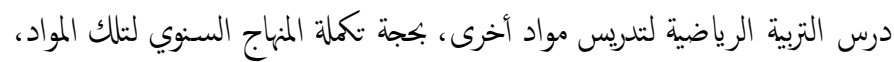

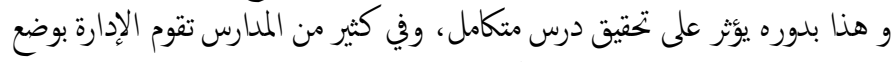

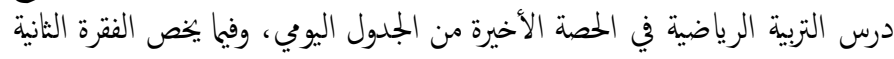

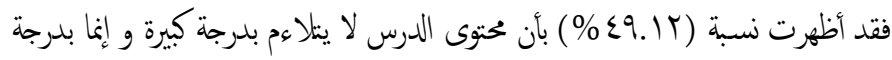

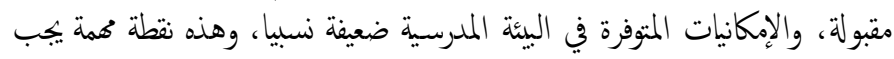

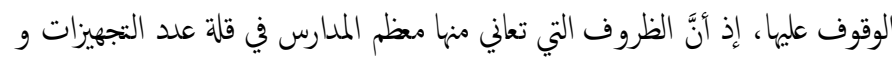

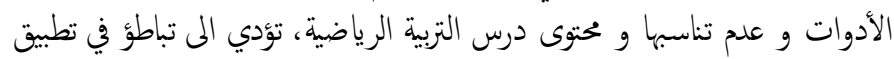

المهارات و هو بالزي الرياضي يساعد بدوره في إظهار الدرس بالمظهر اللائق من جهة ،

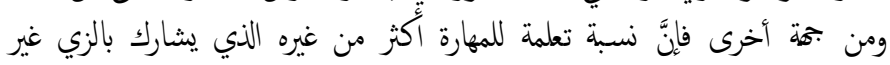
الرياضي.

r.Y عرض ومناقثة تثائج المور الثاني الخاصة بالبئة الملرسية

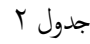

إجابات العينة على فقرات محور البيئة المدرسية

\begin{tabular}{|c|c|c|c|c|}
\hline قليل جدأ\% & قليل \% & متوسط\%\% & كثير\% & البيئة المدرسيّة الثاني: \\
\hline صفر & 19.19 & $0 \vee . \wedge 9$ & Yr.AY & 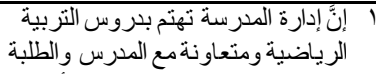 \\
\hline صفر & $1 \varepsilon .4$ & $7 \leqslant .9 Y$ & r...0 & 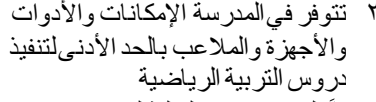 \\
\hline 1.Vo & 10.1. & ०V.^q & $r \leqslant .07$ & 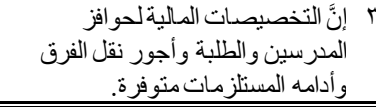 \\
\hline
\end{tabular}

يتيين من الجدول (r) بأن الإجابة على الفقرة الأولى من محور البيئة المدرسية فقد المقال

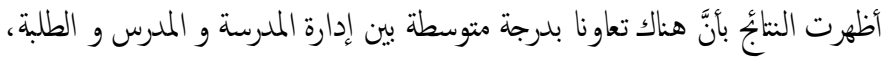

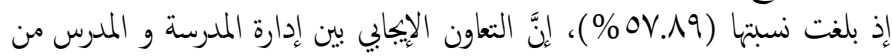

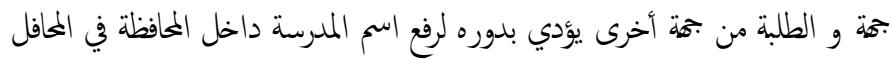

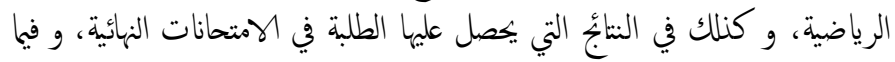

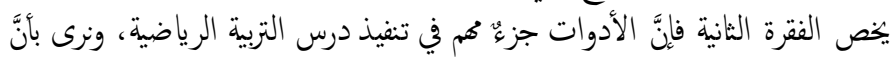

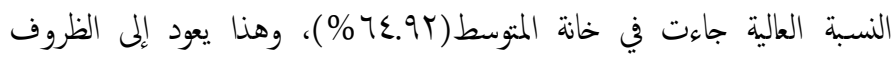

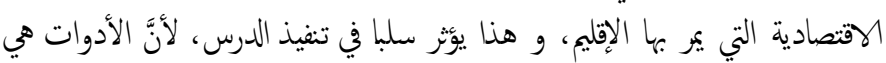

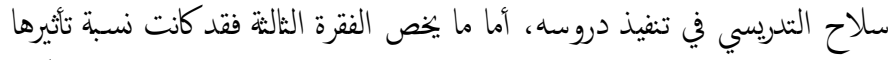

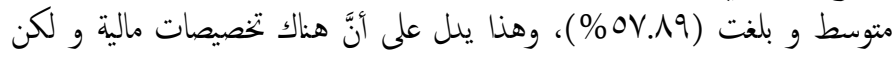

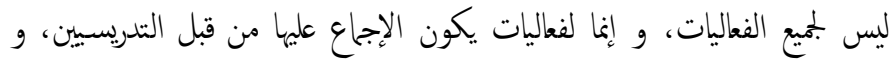

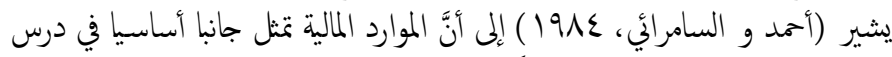

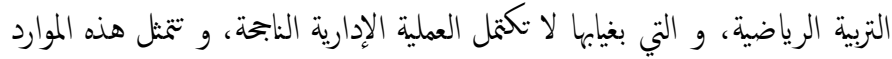

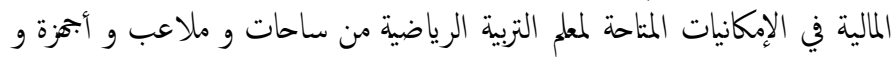

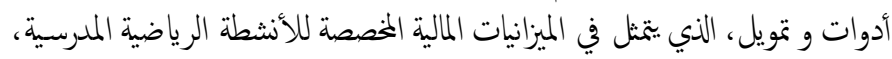

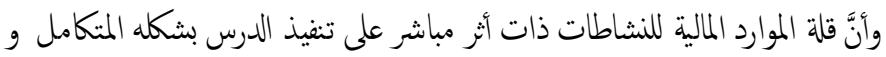

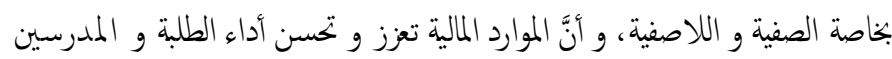

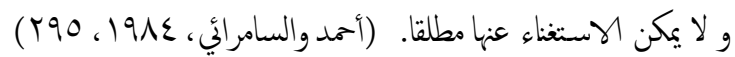

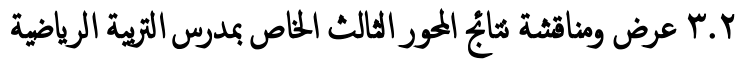

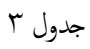

إجابات العينة على فقرات محور مدرس التزبية الرياضية

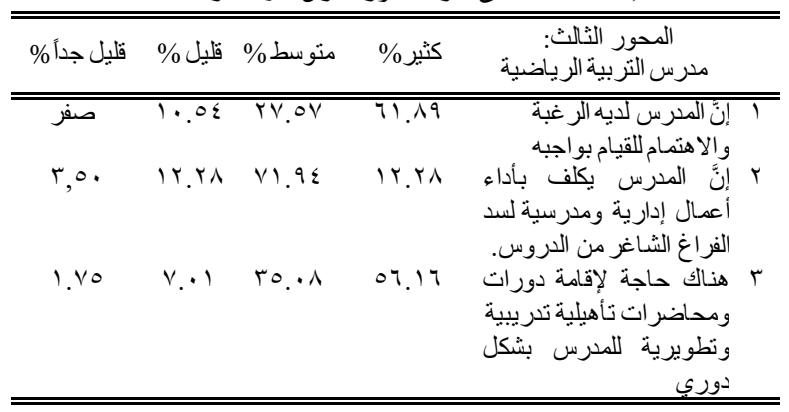


مواطن القوة و تحديد المعوقات و العوامل و المشكلات المؤثرة في بلوغ الأهداف.

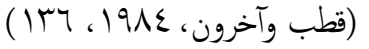

\section{r. الاستنثاجات والتوصيات}

r. الوستناجات

بعد عرض النتأج ومناقشتها توصل الباحث المى الاستناجات الثالية:

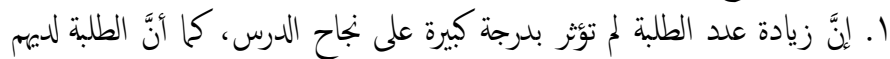
رغبة جيدة للمشاركة في الدرس.

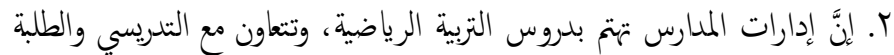

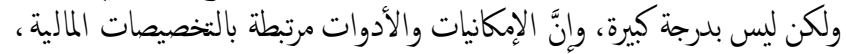

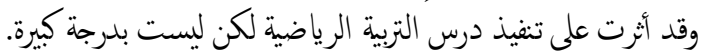

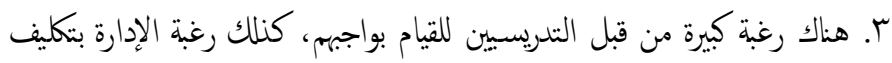

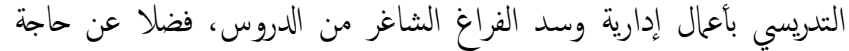

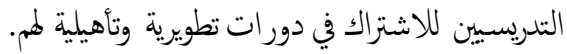

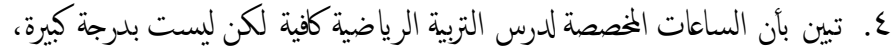

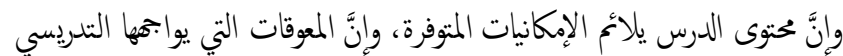

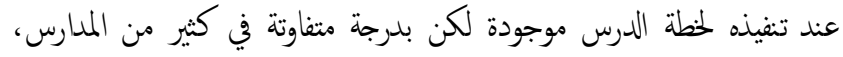

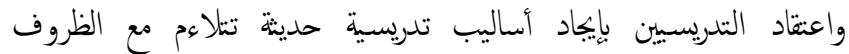

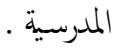

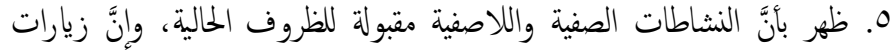

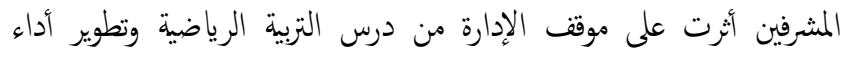

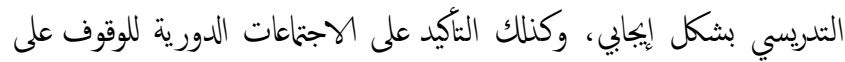
الإيجابيات والسلبيات التي ترافق درس التربية الرياضية وتقوبها.

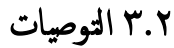

1. العمل على توجيه إدارات المدارس للاهتمام بدروس التربية الرياضية وعدم إجبار

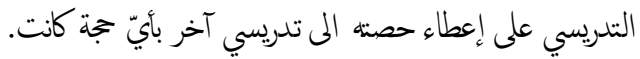

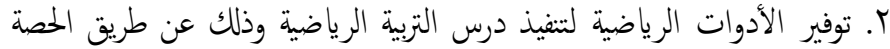
المالية المخصصة السنوية من قبل إدارة المدرسة.

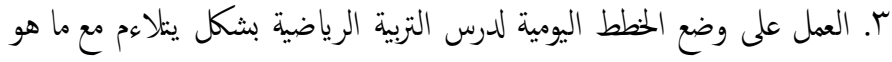
متوفر من أدوات في المدرسة.

ع. استحال أساليب تدريسية متنوعة وحديثة تتناسب مع الظروف المرفية الحالية في المدرسة.

0. إن إقامة الاجتماعات تكون نافذة للندريسيين لعرض آراء ومشاكل واحتياجات

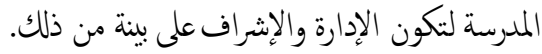

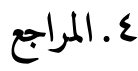

أهمد، بسطويسي والسامرائي، عباس، (عـا91)، طرق التدريس في مجال التربية الرياضية،

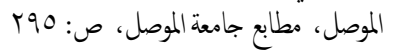

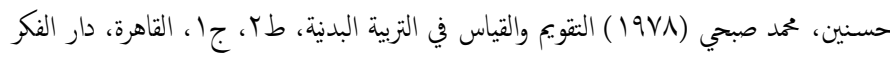

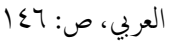

فقرات الدرس بشكلها الصحيح و المتكمل، أما الفقرة الثالثة و التي يككن أن يكون لها إلها

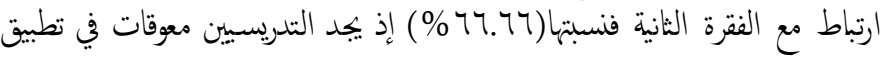

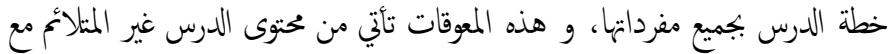

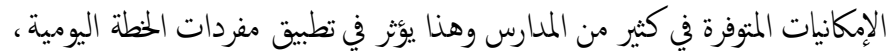

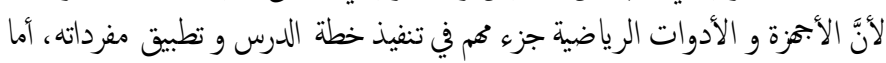

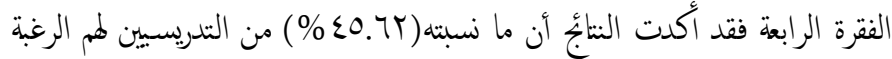

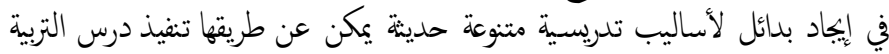

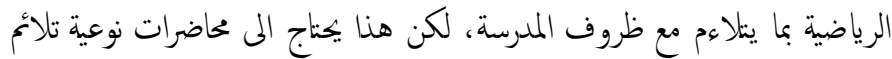

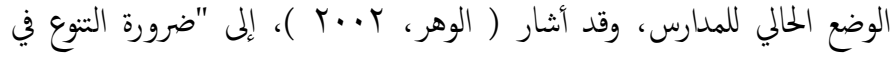

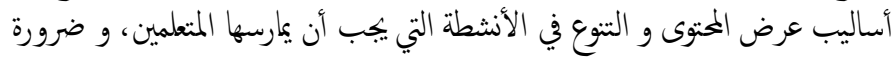

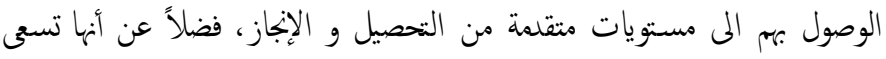

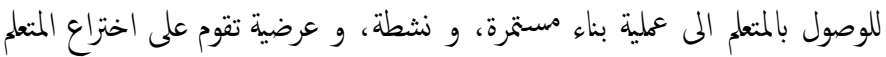

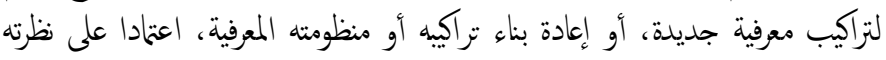

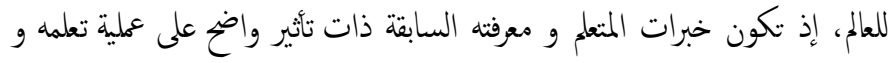

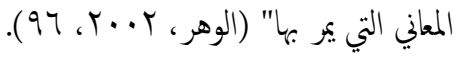

\section{Y. Y عرض ومناقشة كابج المحور الخامس الخاص بالبرامج التبوية والإثراف}

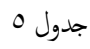

إجابات العينة على فقرات محور البرامج التزبوية والإثراف

\begin{tabular}{|c|c|c|c|c|c|}
\hline قليل جداًّ\% & قليل \% & متوسط\% & كثير\% & البرامج الثربوية والإشر اف الخام: & \\
\hline 1.80 & 10.19 & $7 \leq .94$ & $1 V .0 \varepsilon$ & 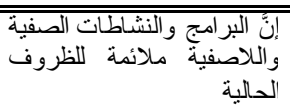 & 7 \\
\hline 1.80 & 10.19 & קוdית & 19.49 & 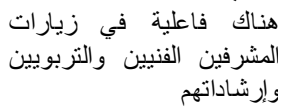 & r \\
\hline 1.80 & 19.49 & or.TE & Tr.T & 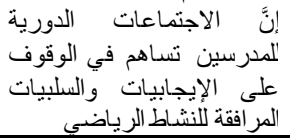 & r \\
\hline
\end{tabular}

فيها يخص الإجابه على الفعرة الاولى من محور البرامج التربويه والإشراق، فإن؛

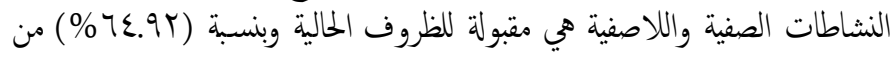

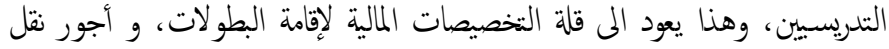

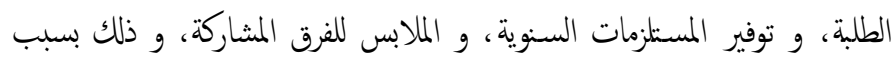

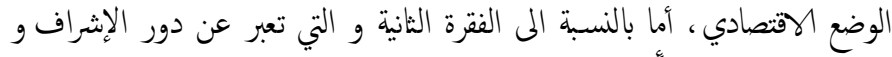

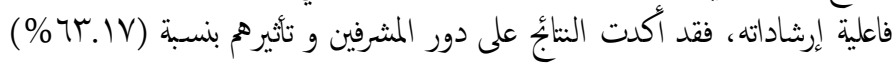

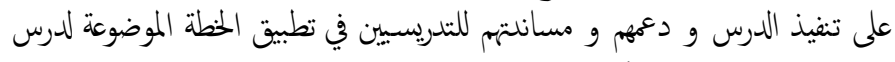

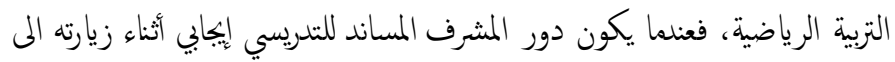

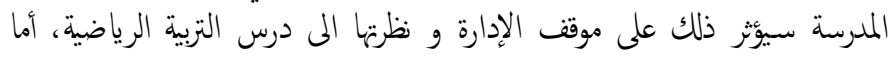

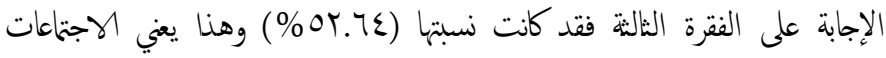

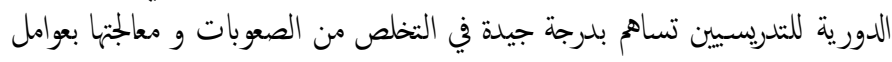

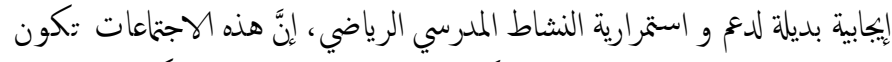

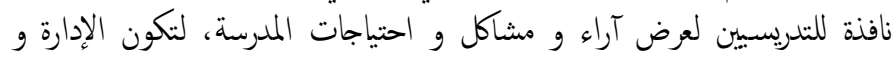

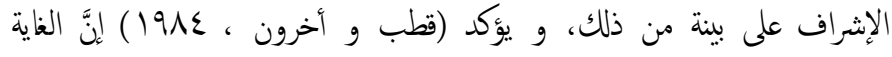

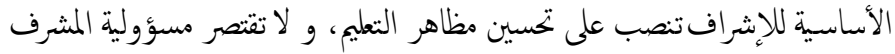

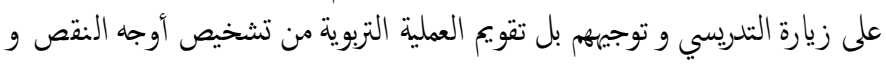




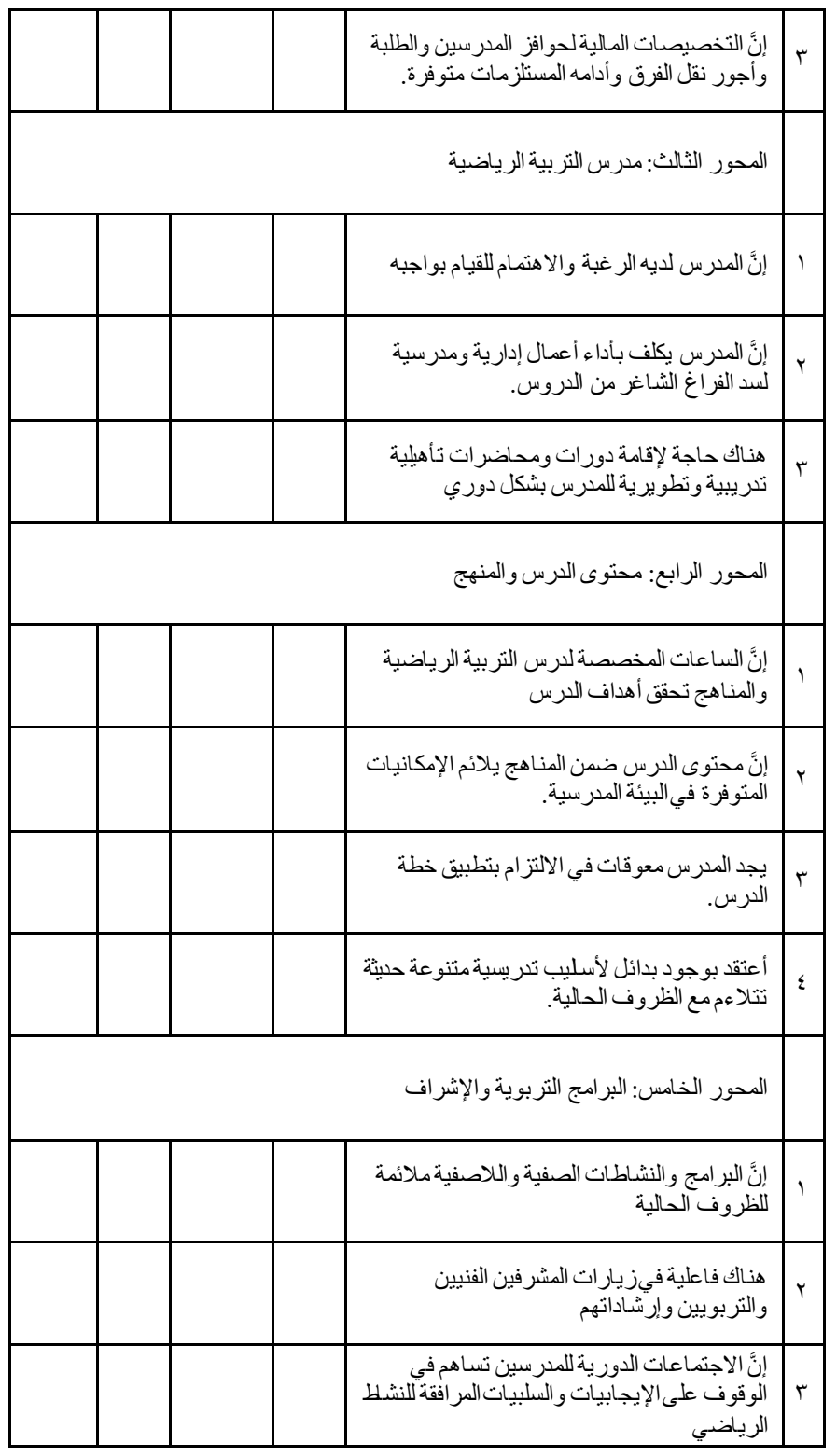

ملحق (r)

\begin{tabular}{|c|c|c|}
\hline مكان العمل & الاختصاص & أسماء السـادة الخبر اء والمختصين \\
\hline جامعة سوران & طر ائق التدريس & أ. دمازن عبد الرحمن \\
\hline جامعة صلاح الدين & طرائق التدريس & أ. د فداء أكرم \\
\hline جامعة كو يه & طر ائق التدريس & أ. د سعيد صـالح \\
\hline جامعة كويه & القياس والتقويم & أ. دكَّران معروف \\
\hline جامعة صلاح الدين & طر ائق التدريس & أ.م. د فر هاد علي \\
\hline جامعة كو ياه & القياس و التقويم & أ.م. د نوز اد حسين \\
\hline جامعة كويه & طرائق التدريس & أ.م. دريَيباز مجيد \\
\hline
\end{tabular}

الديري، علي ومحد، علي (1994)، مناجج التربية الرياضية بين النظرية والتطبيق، طال، الأردن،

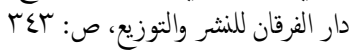

عباس، كمل عبد الحميد (بو1991): التوافق النفسي لدى طلبة المرحلة المتوسطة وعلاقتها بالتحصيل

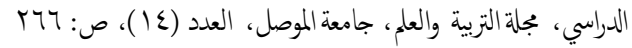

ص: العجيلي، صباح حسين وآخرون (•199 ) التقويم والقياس، جامعة بغداد، مطبعة التعليم العالي،

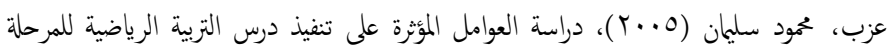

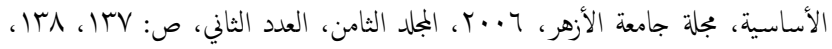

ira

قطب، سعد وآخرون (عی191)، الإدارة والتنظيم في التربية الرياضية، الموصل، دار الكتب للطباعة

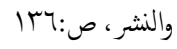

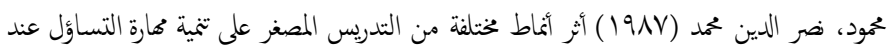

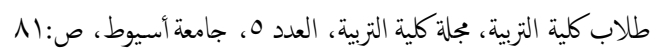

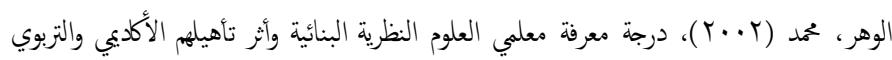

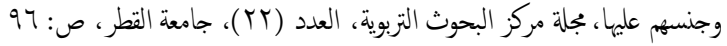

$$
\text { ملحق (1) }
$$

\begin{tabular}{|c|c|c|c|c|c|}
\hline جليل & $\begin{array}{l}\text { قليل } \\
\%\end{array}$ & 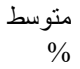 & $\begin{aligned} \text { كثير } \\
\%\end{aligned}$ & المحور الأول: الطلبة & \\
\hline & & & & زيادة عدد الطلبة تؤثر سلباً على نجاح الدرس & 1 \\
\hline & & & & الررسبة والإقبال من قبل الطلبة لمشاركة فعاليات & $r$ \\
\hline & & & & 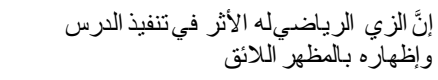 & $r$ \\
\hline & & & & المحور الثاني: البيئة المدرسية & \\
\hline & & & & 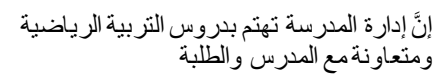 & 1 \\
\hline & & & & والتوفلاعب في بالحد الأدنى الإلتنفيذ دروس الأدوات والتربية الأجهزة & r \\
\hline
\end{tabular}

يقوم الباحث بإجراء بحث بعنوان (تأثثر نسبة مساهمة بعض العوامل في تنفيذ درس التربية الرياضية

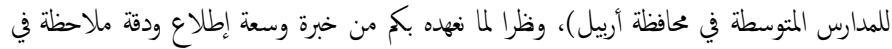

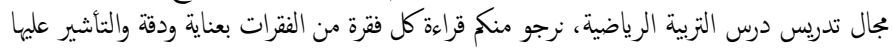

$$
\begin{aligned}
& \text { وذلك بوضع علامة (ل) أمام الفقرة وتحت البديل الذي تجدويه ملائماً. }
\end{aligned}
$$

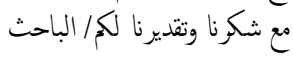

